Wright State University

CORE Scholar

$1-1-1996$

\title{
Effects of in Profile on Material and Device Properties of AlGaAs/ InGaAs/GaAs High Electron Mobility Transistors
}

\author{
David C. Look \\ Wright State University - Main Campus, david.look@wright.edu \\ B. Jogai \\ R. Kaspi \\ J. L. Ebel \\ K. R. Evans
}

See next page for additional authors

Follow this and additional works at: https://corescholar.libraries.wright.edu/physics

Part of the Physics Commons

\section{Repository Citation}

Look, D. C., Jogai, B., Kaspi, R., Ebel, J. L., Evans, K. R., Jones, R. L., Nakano, K., Sherriff, R. E., Stutz, C. E., DeSalvo, G. C., \& Ito, C. (1996). Effects of in Profile on Material and Device Properties of AIGaAs/InGaAs/ GaAs High Electron Mobility Transistors. Journal of Applied Physics, 79 (1), 540-544.

https://corescholar.libraries.wright.edu/physics/131

This Article is brought to you for free and open access by the Physics at CORE Scholar. It has been accepted for inclusion in Physics Faculty Publications by an authorized administrator of CORE Scholar. For more information, please contact library-corescholar@wright.edu. 


\section{Authors}

David C. Look, B. Jogai, R. Kaspi, J. L. Ebel, K. R. Evans, R. L. Jones, K. Nakano, R. E. Sherriff, C. E. Stutz, G. C. DeSalvo, and C. Ito 


\title{
Effects of In profile on material and device properties of AIGaAs/InGaAs/ GaAs high electron mobility transistors
}

\author{
D. C. Look, B. Jogai, and R. Kaspi \\ University Research Center, Wright State University, Dayton, Ohio 45435
}

\begin{abstract}
J. L. Ebel, K. R. Evans, R. L. Jones, K. Nakano, R. E. Sherriff, and C. E. Stutz
Solid State Electronics Directorate, Wright Laboratory, WL/ELD, Wright-Patterson Air Force Base, Ohio 45433
\end{abstract}

G. C. DeSalvo and C. Ito

Northeastern Consortium for Engineering Education, 1101 Massachusetts Avenue, St. Cloud, Florida 34769

(Received 7 August 1995; accepted for publication 5 October 1995)

\begin{abstract}
The molecular-beam-epitaxial growth of $\operatorname{In}_{x} \mathrm{Ga}_{1-x} \mathrm{As}$ on $\mathrm{GaAs}$ or $\mathrm{Al}_{y} \mathrm{Ga}_{1-y} \mathrm{As}$ leads to a variation of In content with depth, due to In segregation. However, by predepositing In at the beginning of $\operatorname{In}_{x} \mathrm{Ga}_{1-x}$ As growth, and also thermally removing the excess In at the end, we can produce a layer with the ideal "square" In profile. We find that the performance of $\mathrm{Al}_{y} \mathrm{Ga}_{1-y} \mathrm{As} / \mathrm{In}_{x} \mathrm{Ga}_{1-x} \mathrm{As} / \mathrm{GaAs}$ high electron mobility transistors is most enhanced by the predeposition step alone. (C) 1996 American Institute of Physics. [S0021-8979(96)08901-6]
\end{abstract}

\section{INTRODUCTION}

Pseudomorphic high electron mobility transistor (pHEMT) structures, involving $\mathrm{Al}_{y} \mathrm{Ga}_{1-y} \mathrm{As} / \mathrm{In}_{x} \mathrm{Ga}_{1-x} \mathrm{As} /$ GaAs quantum wells (QWs), are attaining widespread use in low-noise and power applications requiring high speed. ${ }^{1}$ (In some cases $\mathrm{Al}_{y} \mathrm{Ga}_{1-y} \mathrm{As}$ replaces $\mathrm{GaAs}$ in the region below the $\mathrm{In}_{x} \mathrm{Ga}_{1-x} \mathrm{As}$.) In such structures, the upper $\mathrm{Al}_{y} \mathrm{Ga}_{1-y} \mathrm{As}$ layer is typically doped with a thin sheet of Si ions ( $\delta$ doping) about $30-60 \AA$ above the $\operatorname{In}_{x} \mathrm{Ga}_{1-x} \mathrm{As}$, and the $\mathrm{In}_{x} \mathrm{Ga}_{1-x} \mathrm{As}$ and $\mathrm{GaAs}$ layers are undoped. A large fraction of the electrons from the $\mathrm{Si} \delta$ doping transfer to the $\mathrm{In}_{x} \mathrm{Ga}_{1-x}$ As well because the lowest-energy levels in the well lie below those in the $\delta$ region. Superior performance is achieved because the QW electrons are confined in a material $\left(\mathrm{In}_{x} \mathrm{Ga}_{1-x} \mathrm{As}\right)$ with high mobility and saturation velocity.

Most analyses of pHEMT structures are predicated upon the QW being "square," i.e., having a constant In fraction $(x$ value) from top to bottom. However, it is well known that In tends to "ride the surface" of a growing $\operatorname{In}_{x} \mathrm{Ga}_{1-x}$ As layer, and thus the bottom of the well has too low an In fraction, and the top cannot be characterized by an abrupt cutoff of In. ${ }^{2}$ Obviously this nonideal In profile will affect the optical and electrical properties of the material but there also is a question on how much the device performance is affected. In this work, we explore these questions by characterizing several structures with modified In profiles, and then fabricating and testing state-of-the-art devices on these structures. The characterization techniques are magneto-Hall (M-Hall), double-crystal x-ray diffraction (DCXRD), and photoluminescence (PL), and the results are compared with detailed theoretical calculations. The devices have $0.25 \mu \mathrm{m}$ gate lengths, and current cut-off frequencies of greater than 90 $\mathrm{GHz}$ in some cases. Of the tested structures, the best device results were obtained after a predeposition of In to "square up" the bottom of the QW, but without removal of the top, surface-riding layer of In.

\section{LAYER GROWTH}

The basic material structure used in this study is shown in Fig. 1. The layers were grown in a Varian Gen II system at about $520{ }^{\circ} \mathrm{C}$ with an $\mathrm{As}_{2} / \mathrm{Ga}$ beam equivalent pressure of approximately 20. Above the semi-insulating GaAs substrate, in order, are the following layers: (1) $500 \AA \mathrm{GaAs}$, undoped; (2) 11 period superlattice, $30 \AA \mathrm{GaAs} / 30 \AA$ $\mathrm{Al}_{0.24} \mathrm{Ga}_{0.76} \mathrm{As}$, undoped; (3) $5000 \AA \mathrm{A} \mathrm{GaAs}$, undoped; (4) 100 $\AA \mathrm{GaAs}$, doped $1 \times 10^{18} \mathrm{~cm}^{-3}$; (5) $30 \AA \mathrm{GaAs}$, undoped; (6) $125 \AA \mathrm{In}_{0.22} \mathrm{Ga}_{0.78} \mathrm{As}$, undoped; (7) $40 \AA \mathrm{Al}_{0.24} \mathrm{Ga}_{0.76} \mathrm{As}$, undoped; (8) sheet $(\delta)$ charge of $\mathrm{Si}, 4 \times 10^{12} \mathrm{~cm}^{-2}$; (9) $200 \AA$ $\mathrm{Al}_{0.24} \mathrm{Ga}_{0.76} \mathrm{As}$, doped $5 \times 10^{17} \mathrm{~cm}^{-3}$; (10) $30 \AA$ of AlAs, doped $1.6 \times 10^{19}$; and (11) $350 \AA \mathrm{GaAs}$, doped $5 \times 10^{18} \mathrm{~cm}^{-3}$. Four such structures, designated 1971 $(N), \quad 1972(F)$, 1973(P), and 1974( $P F)$ were grown, but the latter three were modified as follows: 1972(F) had the surface-riding layer of In removed by a "flash off" technique; 1973( $P)$ had the bottom of the well squared-up (uniform In composition) by a controlled predeposition; and 1974( $P F)$ had both a predeposition and a flashoff.

\begin{tabular}{crr}
\hline GaAs:Si & $350 \AA$ & $5 \times 10^{18} \mathrm{~cm}^{-3}$ \\
\hline AlAs:Si & $30 \AA$ & $1.6 \times 10^{19} \mathrm{~cm}^{-3}$ \\
\hline $\mathrm{Al}_{0.24} \mathrm{Ga}_{0.76}$ As:Si & $200 \AA$ & $5 \times 10^{17} \mathrm{~cm}^{-3}$ \\
\hline Si-delta & $4 \times 10^{12} \mathrm{~cm}^{-2}$ \\
\hline $\mathrm{Al}_{0.24} \mathrm{Ga}_{0.76}$ As & $40 \AA$ \\
\hline $\mathrm{In}_{0.22} \mathrm{Ga}_{0.78}$ As & $125 \AA$ \\
\hline GaAs & $30 \AA$ \\
\hline GaAs:Si & $100 \AA$ & $1 \times 10^{18} \mathrm{~cm}^{-3}$ \\
\hline GaAs & $5000 \AA$ \\
\hline
\end{tabular}

Superlattice and $\mathrm{SI}$ GaAs substrate

FIG. 1. The nominal structure of the samples discussed in this study. 


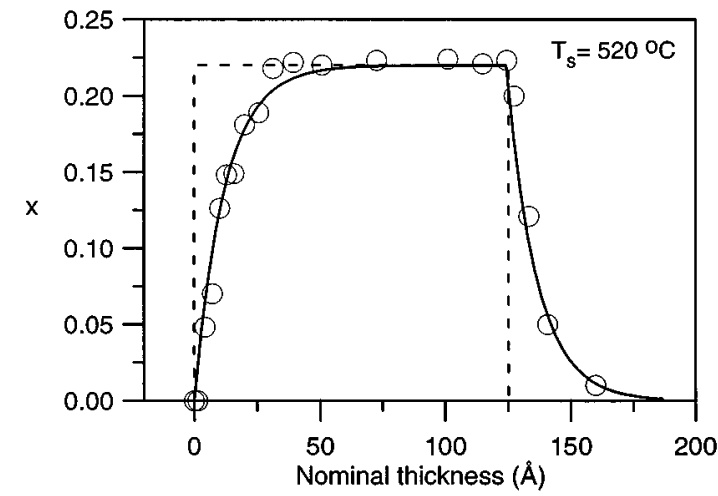

FIG. 2. The value of $x$ vs intended depth for the $\operatorname{In}_{x} \mathrm{Ga}_{1-x}$ As quantum well.

A profile of the actual In concentration in a normal QW, e.g., 1971 $(N)$, is shown in Fig. 2. The method used to determine this profile is discussed in Ref. 3. As seen, the In concentration varies in both the top and bottom regions over a width of $20-30 \AA$. We have also shown, ${ }^{3}$ by using similar methodology, that a predeposition of roughly 1 monolayer of In, depending on substrate temperature, can square up the well at the bottom. ${ }^{3}$ Furthermore, a rapid heating to $565^{\circ} \mathrm{C}$ for about 1 min was shown to desorb the loosely adsorbed In at the top and square up that region. ${ }^{4}$ Thus, we can create QWs with the desired features and determine how they affect pHEMT performance.

\section{X-RAY MEASUREMENTS}

Double-crystal x-ray diffraction (DCXRD) curves were obtained by using a Bede Model QC2a diffractometer. The spectrum for $1974(P F)$, showing the $\mathrm{In}_{x} \mathrm{Ga}_{1-x}$ As peak at $\omega=-4000$ arcsec, is displayed in Fig. 3. Analysis was carried out by fitting this spectrum, and each of the spectra for the other three samples, with a dynamic-scattering theory, ${ }^{5}$ and the results for In concentration and QW width are given in Table I. The uncertainties are approximately $0.5 \%$ for In concentration and $5 \AA$ for QW width. Note that the effective well width is highest for sample $1973(P)$, lowest for sample 1972(F), and in between for samples $1971(N)$ and 1974 $(P F)$. All of these results are expected, since the predeposition "adds width," and the flash-off "removes width." The effective thicknesses are used as input parameters for the theory, discussed below. The In concentrations for all four samples could possibly be equal, within error, although

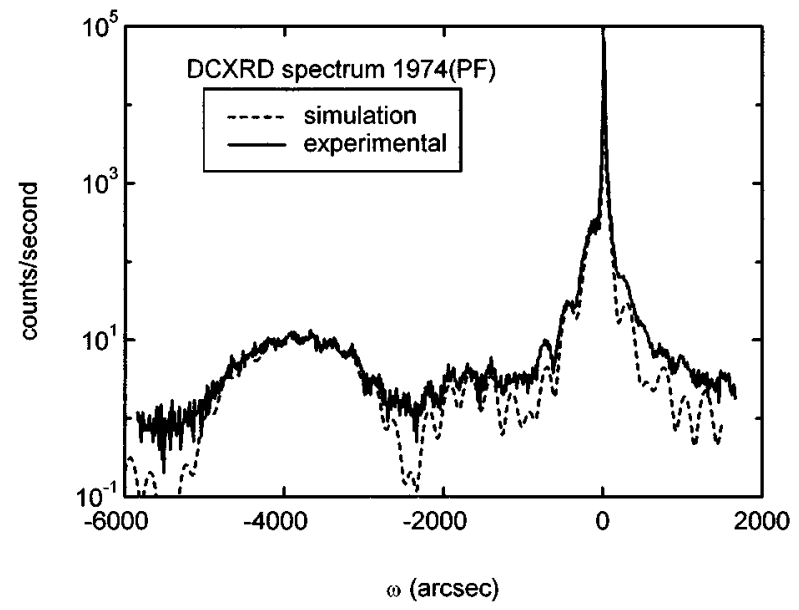

FIG. 3. An experimental DCXRD spectrum (solid line) for sample 1974( $P F)$ along with the simulated spectrum (dashed line).

samples $1973(P)$ and $1974(P F)$ appear to have slightly higher values. All In concentrations are close to the nominal value of $22 \%$.

\section{PHOTOLUMINESCENCE MEASUREMENTS}

Photoluminescence (PL) spectra at $4 \mathrm{~K}$ for samples $1972(F)$ and $1973(P)$ are compared in Fig. 4. The lowerenergy line in each spectrum is E1-H1, i.e., a transition from the lowest conduction subband E1 to the highest heavy-hole subband H1, and the higher-energy PL line is E2-H1, where E2 denotes the conduction subband immediately above E1. The E2-H1 line is parity forbidden in a perfectly square well, but the QWs in our samples are asymmetric, largely because of the $\delta$ doping on the top side only. Also, what might be expected to be a competing PL line, i.e., E1-H2, is weak because $\mathrm{H} 2$ has only a small hole occupation at low temperature. ${ }^{6}$ The relative intensities of the PL lines, i.e., $I(\mathrm{E} 2-\mathrm{H} 1) / I(\mathrm{E} 1-\mathrm{H} 1)$, are well explained by the theoretical oscillator strengths. The experimental ratios for $1972(F)$ and $1973(P)$ are 0.67 and 3.6, respectively, and the predicted ratios are 0.52 and 4.1 .

In Table I, we denote the E1-H1 and E2-H1 transition energies by E1 and E2, respectively. These energies are compared with theoretical values and behave qualitatively as expected. For example, sample 1973( $P$ ) has the effectively widest QW and the most In, and thus should have the lowest transition energies, as observed.

TABLE I. X-ray, photoluminescence, and theoretical data.

\begin{tabular}{|c|c|c|c|c|c|c|c|}
\hline \multirow[b]{2}{*}{ Wafer } & \multicolumn{2}{|c|}{$\mathrm{X}$ ray } & \multicolumn{2}{|c|}{ PL } & \multicolumn{3}{|c|}{ Theory } \\
\hline & In & $\begin{array}{c}\text { QW } \\
\text { thickness }\end{array}$ & $\begin{array}{c}\text { E1 } \\
(\mathrm{eV})\end{array}$ & $\begin{array}{c}\mathrm{E} 2 \\
(\mathrm{eV})\end{array}$ & $\begin{array}{c}\text { E1 } \\
(\mathrm{eV})\end{array}$ & $\begin{array}{c}\mathrm{E} 2 \\
(\mathrm{eV})\end{array}$ & $\begin{array}{c}n_{2 \mathrm{D}} \\
\left(\mathrm{cm}^{-2}\right)\end{array}$ \\
\hline $1971(N)$ & $21 \%$ & $135 \AA$ & 1.2352 & 1.3000 & 1.268 & 1.337 & $3.46 \times 10^{12}$ \\
\hline $1972(F)$ & $21 \%$ & $110 \AA$ & 1.2445 & 1.3110 & 1.295 & 1.372 & $3.30 \times 10^{12}$ \\
\hline $1973(P)$ & $22 \%$ & $140 \AA$ & 1.2146 & 1.2642 & 1.244 & 1.304 & $3.61 \times 10^{12}$ \\
\hline $1974(P F)$ & $22 \%$ & $125 \AA$ & 1.2224 & 1.2739 & 1.259 & 1.320 & $3.47 \times 10^{12}$ \\
\hline
\end{tabular}




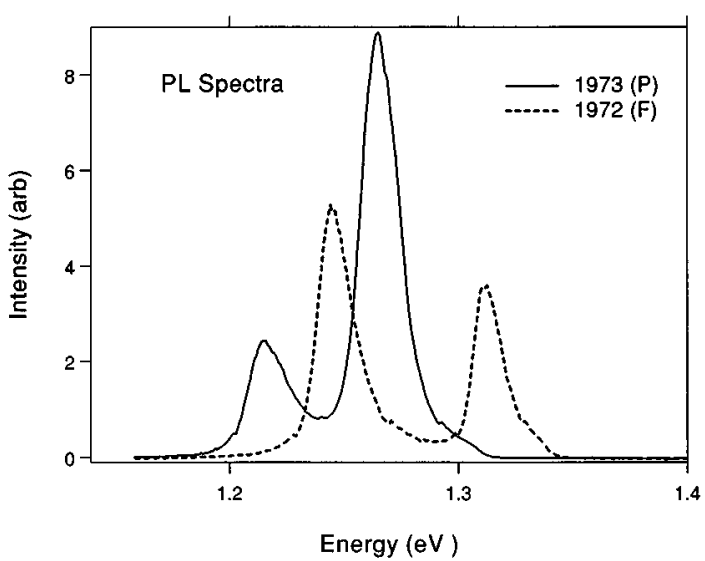

FIG. 4. Photoluminescence spectra at $4 \mathrm{~K}$ for samples $1972(F)$ and 1973(P).

\section{MAGNETO-HALL MEASUREMENTS}

Standard Hall-effect measurements give erroneous results on pHEMT materials because the two-dimensional (2D) electrons in the QW and the electrons in the GaAs cap layer have roughly equal conductances, especially at room temperature, and thus both strongly influence the Hall coefficient. (The doped $\mathrm{Al}_{0.24} \mathrm{Ga}_{0.76} \mathrm{As}$ barrier layer has fewer electrons and lower mobility, and therefore does not influence the electrical properties to any significant extent.) Fortunately, however, two-layer systems such as this often have strong magnetic-field dependences of the conductance and Hall coefficient and this information can be analyzed to give values of the mobility $\mu$ and carrier concentration $n$ for both layers. ${ }^{7,8}$ In Table II we present values of $\rho_{2 \mathrm{D}}, \mu$, and $n_{2 \mathrm{D}}$ at 296 and $77 \mathrm{~K}$; it should be noted that $\rho_{2 \mathrm{D}}$ and $n_{2 \mathrm{D}}$ are areal (not volume) parameters. Also note that the values of $n_{2 \mathrm{D}}$ at $296 \mathrm{~K}$ are consistently $10 \%-20 \%$ higher than those at $77 \mathrm{~K}$, even though the theory predicts that they should be nearly equal. The reasons for this disagreement are not known, but it also should be pointed out that the $296 \mathrm{~K}$ values of $n_{2 \mathrm{D}}$ are within about $5 \%$ of the theoretical predictions (Table I) for all four samples.

The relative magnitudes of the 2D carrier concentrations are quite predictable based on the expected In profile in the QW. For example, sample 1974( $P F)$ has had In added at the bottom and removed from the top of the QW, so that the net effect should be small (except for a slight increase in the effective spacer layer); indeed, $n$ is about the same as that in

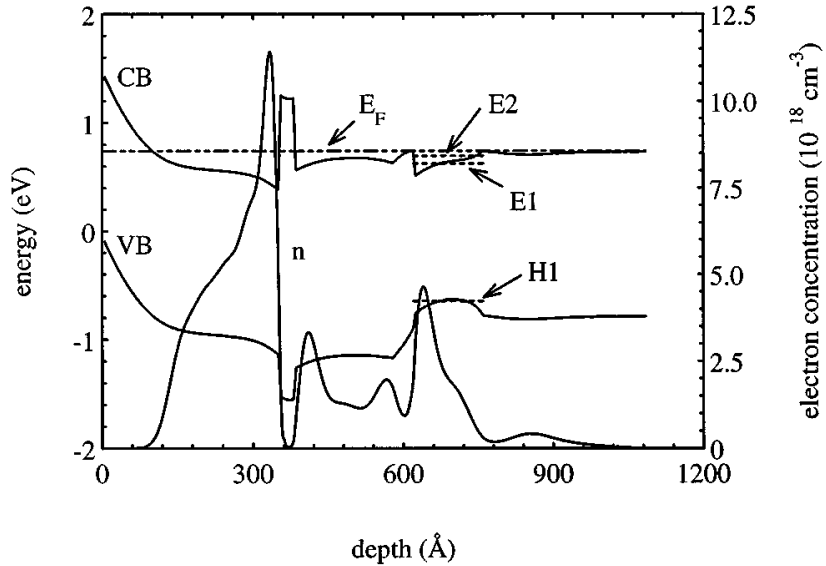

FIG. 5. Theoretical profiles of the conduction band (CB), valence band (VB), and electron concentration $(n)$. Also shown are the subbands (E1, E2, and $\mathrm{H} 1)$ and Fermi level $\left(E_{F}\right)$.

sample 1971 $(N)$, for which no modifications were made. Also, as expected, sample $1972(F)$ has the smallest $n$ and $1973(P)$ the largest, since the former has had only the removal of In, and the latter, only the addition. The reason for these effects is that more In at the edge of the QW either increases the average In content or effectively widens the well (mostly the latter), and both of these changes lower the conduction subband energies and promote more electron transfer.

\section{THEORY}

Theoretical calculations were based on a four-band $k \cdot p$ calculation of the band structure coupled self-consistently with a solution of the Poisson equation. ${ }^{9,10}$ The strain Hamiltonian included strain-induced band mixing as well as straininduced corrections to the spin-orbit interaction. The exchange-correlation potential was calculated from densityfunctional theory within the local-density approximation. The well shapes (i.e., In profiles) were modeled with approximately exponential rises and falls of the In content, as directly measured and shown in Fig. 2. Thus, the modeled In profile in sample 1971 $(N)$ looked much like the profile in Fig. 2, that of $1972(F)$ had the top squared off, that of 1973( $P)$ had the bottom squared off, and that of 1974(PF) had both the top and bottom squared off. A diagram of the bands and electron concentration for sample $1971(N)$ is pre-

M-Hall

\begin{tabular}{|c|c|c|c|c|c|c|c|c|}
\hline \multirow[b]{2}{*}{ Wafer } & \multicolumn{3}{|c|}{$296 \mathrm{~K}$} & \multicolumn{3}{|c|}{$77 \mathrm{~K}$} & \multicolumn{2}{|c|}{ Device } \\
\hline & $\begin{array}{c}\rho_{2 \mathrm{D}} \\
(\Omega / \square)\end{array}$ & $\begin{array}{c}\mu \\
\left(\mathrm{cm}^{2} / \mathrm{V} \mathrm{s}\right)\end{array}$ & $\begin{array}{c}n_{2 \mathrm{D}} \\
\left(\mathrm{cm}^{-2}\right)\end{array}$ & $\begin{array}{c}\rho_{2 \mathrm{D}} \\
(\Omega / \square)\end{array}$ & $\begin{array}{c}\mu \\
\left(\mathrm{cm}^{2} / \mathrm{V} \mathrm{s}\right)\end{array}$ & $\begin{array}{c}n_{2 \mathrm{D}} \\
\left(\mathrm{cm}^{-3}\right)\end{array}$ & $\underset{(\mathrm{mS} / \mathrm{mm})}{g_{\mathrm{mp}}}$ & $\begin{array}{c}f_{t} \\
(\mathrm{GHz})\end{array}$ \\
\hline $1971(N)$ & 299.0 & 5950 & $3.51 \times 10^{12}$ & 132.1 & 14730 & $3.21 \times 10^{12}$ & 374 & 80.0 \\
\hline $1972(F)$ & 299.9 & 6640 & $3.22 \times 10^{12}$ & 125.6 & 18890 & $2.63 \times 10^{12}$ & 391 & 79.4 \\
\hline $1973(P)$ & 280.7 & 5750 & $3.86 \times 10^{12}$ & 119.6 & 14310 & $3.64 \times 10^{12}$ & 441 & 93.4 \\
\hline $1974(P F)$ & 271.4 & 6470 & $3.56 \times 10^{12}$ & 114.4 & 17380 & $3.14 \times 10^{12}$ & 418 & 72.5 \\
\hline
\end{tabular}




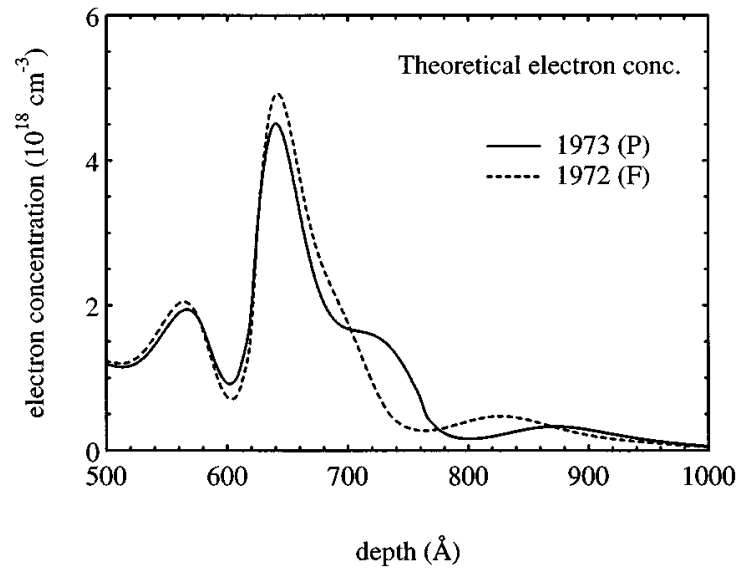

FIG. 6. Electron profiles for samples 1972(F) and 1973(P).

sented in Fig. 5, and the transition energies E1-H1, E2-H1, and the carrier concentration are presented in Table I and designated E1, E2, and $n_{2 \mathrm{D}}$, respectively. The latter was determined by integrating $n$ in the QW region from the minimum near $600 \AA$, preceding the peak, to the minimum near $780 \AA$ A. Although these integration limits are somewhat arbitrary, they do produce values of $n_{2 \mathrm{D}}$ within $5 \%$ of those determined experimentally by the M-Hall technique (Table II). The theoretical energies are systematically above the measured PL energies by about $30 \mathrm{meV}$. Although this is not a large discrepancy, it is presently being investigated by testing sensitivity to some of the assumptions in the theory. Alternatively, small, systematic errors in the well thicknesses or In content could also explain the discrepancy.

In Fig. 6 we compare the electron profiles of 1972( $F)$ and $1973(P)$. The most outstanding difference is the increased electron concentration near the bottom of the well in $1973(P)$ due to the greater In content. Part of the increase in $1973(P)$ is due to transfer from the existing electron distribution (note the decrease in the peak near $640 \AA$ ), but most is due to transfer from the underdoping.

\section{DEVICE FABRICATION AND DISCUSSION}

The pHEMT devices fabricated on structures 1971-1974 contained two gate fingers, each $50 \mu \mathrm{m}$ wide and $0.25 \mu \mathrm{m}$ long, and mushroomed at the top to produce a lower gate resistance. The devices were tested up to $40 \mathrm{GHz}$, and the current cut-off frequency $f_{t}$ was measured from a $6 \mathrm{db} /$ octave extrapolation of the common-source short-circuit current gain $\left|h_{21}\right|$ to unity gain. In all cases, the measured data up to $40 \mathrm{GHz}$ also decreased with frequency by about $6 \mathrm{db} /$ octave; thus, the $f_{t}$ values are realistic. About 15 devices were measured on each wafer, and the top 5, with respect to $f_{t}$, were chosen for analysis. The means of these 5 , for each wafer, are listed in Table II, and are plotted on the ordinate in Fig. 7. The error bar on each $f_{t}$ point in Fig. 7 is two standard deviations in magnitude. The M-Hall values of $n_{2 \mathrm{D}}$, plotted on the abscissa, are the mean values derived from three or four unprocessed drop-outs taken from various locations on the completely fabricated wafers. Again, the error bars comprise two standard deviations. Sample 1974(PF)

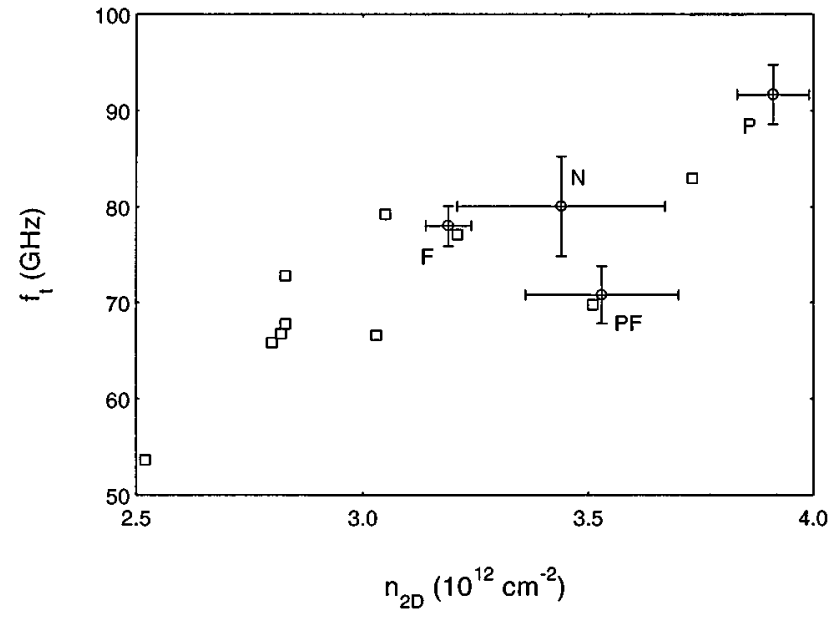

FIG. 7. The current cut-off frequency $f_{t}$ vs QW electron concentration $n_{2 \mathrm{D}}$, determined by M-Hall measurements, for $0.25 \mu \mathrm{m}$ gate-length devices 1971(N), 1972(F), 1973(P), and 1974(PF). Also shown, with square symbols, are the $f_{t}$ 's (multiplied by a factor 4 ) for several $1.0 \mu \mathrm{m}$ gatelength devices.

was anomalous in that the transconductance peak $g_{\mathrm{mp}}$ occurred at a gate-source voltage $V_{\mathrm{gs}}$ of $-0.2 \mathrm{~V}$, whereas $g_{\mathrm{mp}}$ for the other three samples occurred at $V_{\mathrm{gs}} \simeq-0.8$ to $-0.9 \mathrm{~V}$. Also, $I_{\mathrm{dss}}$ was much lower, suggesting that the AlGaAs barrier layer may have been less than $200 \AA$ thick or that the gate recess etch may have proceeded beyond the AlAs etchstop layer. Because of this problem, we do not include sample 1974 in the analysis to follow.

Along with the data for samples 1971-1974, some normalized $f_{t}$ values for several other devices are plotted in Fig. 7. These devices had gate lengths of $1 \mu \mathrm{m}$, so that their $f_{t}$, s had to be multiplied by a factor of 4 to effect a rough normalization. Interestingly enough, the normalization seems reasonably valid, as can be seen by comparing $f_{t}$ values near $n_{2 \mathrm{D}}=3.2 \times 10^{12} \mathrm{~cm}^{-2}$. Taken together, the two data sets are consistent with a roughly $50 \%$ increase in $f_{t}$ as $n_{2 \mathrm{D}}$ increases from 2.5 to $4.0 \times 10^{12} \mathrm{~cm}^{-2}$.

Because the carrier concentration $n_{2 \mathrm{D}}$ in samples 19711974 monotonically varies with effective well width $w$ (compare column 4 in Table II with column 3 in Table I), it could be questioned whether $f_{t}$ is actually more directly influenced by $w$ than $n_{2 \mathrm{D}}$. However, the other samples (of $1 \mu \mathrm{m}$ gate length) illustrated in Fig. 7 also showed a strong $f_{t}$ vs $n_{2 \mathrm{D}}$ variation, and they each had identical In profiles in their QWs. (Their $n_{2 \mathrm{D}}$ 's were varied by underdoping changes.) Thus, the well width itself does not seem to be a dominant factor in the $f_{t}$ variation.

The intrinsic $f_{t}$ in a short-gate-length device is often written as $v_{s} / 2 \pi l_{g}$, where $v_{s}$ is the saturation velocity and $l_{g}$ is the gate length. For pure $\operatorname{In}_{0.22} \mathrm{Ga}_{0.78} \mathrm{As}$, a recent calculation ${ }^{11}$ gives $v_{s}=1.1 \times 10^{7} \mathrm{~cm} / \mathrm{s}$, which would lead to $f_{t} \simeq 70 \mathrm{GHz}$ for a $0.25 \mu \mathrm{m}$ device. This value of $f_{t}$ is well below what we and others have measured for such devices, and the reason is that the electrons probably experience significant velocity overshoot because they cannot attain saturation in the small gate traversal time, $l_{g} / v_{s} \simeq 1-2 \mathrm{ps} .{ }^{12}$ The 
effective saturation velocity $v_{\text {se }}$, which would apply to the $f_{t}$ calculation, would thus be intermediate between $v_{s}$ and the peak velocity, $v_{p} \simeq 2.1 \times 10^{7} \mathrm{~cm} / \mathrm{s}$. The value of $v_{\text {se }}$ will increase with increasing In content and with increasing distance of the electron profile from the ionized donor concentration $N_{D}^{+}$. In a comparison between $1972(F)$ and $1973(P)$ we see from Fig. 6 that the additional electrons in the latter are positioned near the bottom of the well; thus, they "see" a relatively high In content, because of the predeposition, and also are quite far from the high $N_{D}^{+}$concentration in the $\delta$ region. These circumstances suggest that $f_{t}$ should be higher in $1973(P)$ than $1972(F)$, as observed.

We next consider extrinsic factors, namely parasitic capacitances and resistances. By considering a common equivalent-circuit diagram, such as that given in Ref. 13, the extrinsic $f_{t}$ can be approximately written as

$$
f_{t}^{\mathrm{ext}}=\frac{v_{s} / 2 \pi l_{g}}{\left(1+C_{\mathrm{dg}} / C_{\mathrm{gs}}\right)\left[1+\left(R_{s}+R_{d}\right) g_{\mathrm{ds}}\right]+\left(C_{\mathrm{dg}} / C_{\mathrm{gs}}\right) g_{m}\left(R_{s}+R_{d}\right)},
$$

where $C_{\mathrm{dg}}$ and $C_{\mathrm{gs}}$ are the drain-gate and gate-source capacitances, respectively, $g_{\mathrm{ds}}$ and $g_{m}$ are the output conductance and transconductance, respectively, and $R_{s}$ and $R_{d}$ are the source and drain resistances, respectively. For the highest possible $v_{\mathrm{se}} \simeq 2.1 \times 10^{7} \mathrm{~cm} / \mathrm{s}$, and $l_{g}=0.25 \mu \mathrm{m}$, we would expect that $f_{t} \simeq 134 \mathrm{GHz}$ without any parasitic effects. Fits to the equivalent circuit diagram mentioned above give intrinsic $f_{t}$ 's of about 130 and $102 \mathrm{GHz}$ for $1973(P)$ and $1972(F)$, respectively, which would suggest parasitic reduction factors [denominator in Eq. (1)] of about 1.4 and 1.3 in the two cases. Thus, intrinsic rather than parasitic effects seem to be of the most importance in the relative performance of these devices. The intrinsic values of $f_{t}$ given above would predict effective velocities of about $2.0 \times 10^{7}$ and $1.6 \times 10^{7} \mathrm{~cm} / \mathrm{s}$ for $1973(P)$ and $1972(F)$, respectively, if $l_{g}=0.25 \mu \mathrm{m}$. (Scanning electron microscopy results give $l_{g}=0.25 \mu \mathrm{m}$, within error, for both samples.)

From the above considerations, we believe that the higher $f_{t}$ in sample $1973(P)$ results mainly from the addition of electrons in a region which has a relatively high In content and is far from the major scattering centers. The increased $n$ is due to the predeposition of In near the bottom of the well, which promotes electron transfer from the underdoping, and causes an overall shift of electrons toward the bottom. Further experiments along with analyses of equivalent-circuit diagrams are planned for the future, but our results here indicate that a predeposition of In in the QW increases the rf performance of the device. Conversely, the flashoff of the excess In at the top of the well has not been shown to have a beneficial effect in this study.

\section{ACKNOWLEDGMENTS}

We wish to thank T. A. Cooper, W. Rice, and C. Isbill for technical assistance, J. E. Ehret and E. N. Taylor for MBE growth, and R. Heil for manuscript preparation. Also, valuable contributions from several members of the heterostructure transistor team, including C. Bozada, R. Dettmer, C. Havasy, T. Quach, and G. D. Via, are gratefully acknowledged. Finally, discussions with R. Anholt were extremely helpful. The work of D.C.L., B.J., and R.K. was supported under US Air Force Contract F33615-95-C-1619 and that of G.D. and C.I., under US Air Force Contract F33615-92-C1056. Further support was received from the Advanced Research Projects Agency. All work was performed at the Solid State Electronics Directorate of Wright Laboratory, WrightPatterson Air Force Base.

${ }^{1}$ J. M. Ballingall, P. A. Martin, J. Mazurowski, P. Ho, P. C. Chao, P. M. Smith, and K. H. G. Duh, Thin Solid Films 231, 95 (1993).

${ }^{2}$ J. M. Moison, C. Guille, F. Houzay, F. Barthe, and M. Van Rompay, Phys. Rev. B 40, 6149 (1989)

${ }^{3}$ R. Kaspi and K. R. Evans, Appl. Phys. Lett. 67, 819 (1995).

${ }^{4}$ K. R. Evans, R. Kaspi, J. E. Ehret, M. Skowronski, and C. R. Jones, J. Vac. Sci. Technol. B 13, 1820 (1995).

5 "Rocking Curve Analysis by Dynamical Simulation, Version 2.0, 1993": Bede Scientific Instruments, Ltd., Lindsey Park, Bowburn, Durham DH6 $5 \mathrm{PF}, \mathrm{UK}$

${ }^{6}$ P. W. Yu, B. Jogai, T. J. Rogers, P. A. Martin, and J. M. Ballingall, J. Appl. Phys. 76, 7535 (1994).

${ }^{7}$ D. C. Look, C. E. Stutz, and C. A. Bozada, J. Appl. Phys. 74, 311 (1993).

${ }^{8}$ D. C. Look, B. Jogai, C. E. Stutz, R. E. Sherriff, G. C. DeSalvo, T. J. Rogers, and J. M. Ballingall, J. Appl. Phys. 76, 328 (1994).

${ }^{9}$ B. Jogai, P. W. Yu, and D. C. Streit, J. Appl. Phys. 75, 1586 (1994).

${ }^{10}$ B. Jogai, J. Appl. Phys. 76, 2316 (1994).

${ }^{11}$ J. L. Thobel, L. Baudry, A. Cappy, P. Bourel, and R. Fauquembergue, Appl. Phys. Lett. 56, 346 (1990).

${ }^{12}$ C. C. Sun, J. M. Xu, A. Hagley, R. Surridge, and A. Springthorpe, Appl. Phys. Lett. 57, 566 (1990).

${ }^{13}$ Y-J. Chen and D. Pavlidis, IEEE Trans. Electron Devices ED-38, 1999 (1991). 